\title{
Long-term hydrologic impact assessment of non-point source pollution measured through land use/land cover (LULC) changes in a tropical complex catchment
}

\begin{abstract}
The contribution of non-point source pollution (NPS) to the contamination of surface water is an issue of growing concern. Non-point source (NPS) pollutants are of various types and altered by several site-specific factors making them difficult to control due to complex uncertainties involve in their behavior. Kelantan River basin, Malaysia is a tropical catchment receiving heavy monsoon rainfall coupled with intense land use/land cover (LULC) changes making the area consistently flood prone thereby deteriorating the surface water quality in the area. This study was conducted to determine the spatio-temporal variation of NPS pollutant loads among different LULC changes and to establish a NPS pollutant loads relationships among LULC conditions and sub-basins in each catchment. Four pollutants parameters such as total suspended solids (TSS), total phosphorus (TP), total nitrogen (TN) and ammonia nitrogen (AN) were chosen with their corresponding event mean concentration values (EMC). Soil map and LULC change maps corresponding to 1984, 2002 and 2013 were used for the calculation of runoff and NPS pollutant loads using numeric integration in a GIS environment. Analysis of Variance (ANOVA) was conducted for the comparison of NPS pollutant loads among the three LULC conditions used and the sub-basins in each catchment. The results showed that the spatio-temporal variation of pollutant loads in almost all the catchments increased with changes in LULC condition as one moves from 1984 to 2013, with 2013 LULC condition found as the dominant in almost all cases. NPS pollutant loads among different LULC changes also increased with changes in LULC condition from 1984 to 2013. While urbanization was found to be the dominant LULC change with the highest pollutant load in all the catchments. Results from ANOVA reveals that statistically most significant $(\mathrm{p}<0.05)$ pollutant loads were obtained from 2013 LULC conditions, while statistically least significant $(\mathrm{p}<0.05)$ pollutant loads were obtained under 1984 LULC condition. This reveals the clear effect of LULC changes on NPS pollution. The findings of this study may be useful to water resource planners in controlling water pollution for future planning.
\end{abstract}

Keyword : Hydrologic impact; Remote sensing; Non-point source pollution; GIS; Malaysia 